\title{
Level of Exclusive Breastfeeding and Its Enabling Factors Among Lactating Women Who Delivered in Health Facilites of Asosa Town, Ethiopia: a Cross Sectional Study
}

\author{
Megersa Kumera \\ Ethiopian Pediatric Society, Addis Ababa, Ethiopia \\ Jemal Haidar ( $\sim$ hjemal@gmail.com ) \\ Addis Ababa University, Addis Ababa University
}

\section{Research Article}

Keywords: Lactating mothers, exclusive breastfeeding practice score, enabling factors, Ethiopia

Posted Date: April 21st, 2021

DOl: https://doi.org/10.21203/rs.3.rs-429676/v1

License: (c) (1) This work is licensed under a Creative Commons Attribution 4.0 International License.

Read Full License 


\section{Abstract}

Background: Despite the enormous benefit of exclusive breastfeeding (EBF) to mothers and infants, the practice of exclusive breastfeeding is globally low. In sub-Saharan Africa and Ethiopia, the prevalence of EBF stands at $35 \%$ and $58 \%$, respectively. The low EBF practice in Ethiopia calls for further study and thus we studied the EBF practice in the study area since little is known about its current magnitude and factors influencing its practice for some programmatic improvements.

Methods: A cross-sectional study was conducted from June-July 2019 among 412 mothers who delivered in health facilities of Asosa town. Data on socio demographic characteristics and other important variables were collected through face to face interview by trained health extension workers in accordance with relevant ethical guidelines and regulations. The collected data were then cleaned and entered into Epi-data software version 3.02. Analysis was done by SPSS version 20. Binary and multivariate logistic regression were performed to identify the contributing factors. P-value of less than 0.05 and $95 \%$ confidence interval was considered to determine statistical significance.

Results: Of the 412 respondents, the majority (88.1\%) were multi-gravida and above. Less than a quarter (26.0\%) and over half (55.4\%) had neither received antenatal nor postnatal care. The proportion of mothers who exclusively breastfed their children was $76.0 \%$ and the overall aggregated good practice of EBF score was $64.1 \%$. mothers who completed primary school [AOR=4.5; $95 \% \mathrm{Cl}=1.1,18.2]$, had three or more ANC [AOR=0.018;95Cl=0.003-0.12], and postnatal follow-up [AOR=0.218;95\% $\mathrm{Cl}=0.07-0.67]$, and had male infants $[A O R=2.3 ; 95 \% \mathrm{Cl}=1.0-4.95]$ were among the enabling factors influencing the exclusive breastfeeding practice score.

Conclusion: Women's retention on the continuum of the maternal care pathway is low with about a quarter of mothers were not practicing EBFand one in two had no postnatal care. To narrow the observed maternal and child health disparities, it is essential to intervene through focused actions that address the above enabling factors.

\section{Introduction}

Exclusive breastfeeding (EBF) has been defined as provision of breast milk only to infants from their biological mothers wet nurses' expressed milk with the exception of medicines (1). Feeding breast milk (BM) alone for the first six months of life is adequate because it contains all the necessary nutrient requirements in terms of quantity as well as quality in addition to its immunological properties which protecs the infants from frequent illnesses and improves his/her chance of survival (2).

It is widely documented that the first year of life is very central for all growing child in improving the quality of life and thus nature has provided them with is a pefect natural food that contains all the essential nutrients needed for growth and development. To maximize the benefits obtained from BM, infants need to be fed demand at least 8 times in 24 hours (3). Infants that are exclusively breastfed are often healthier than their counterparts during their first year of life and consequently retards their growth 
(4). Other benfits documented are economical such as reducing healthcare costs $(5,6)$ improving maternal-child bonding, lowering the risk of developing non communicable diasese and beyond (7).

Breast milk is the healthiest form of milk for human babies with few exceptions like when the mother is taking certain drugs or is infected with tuberculosis or HIV (8). Because of its enormous benefits, researchers advise the use of human milk to feed their babies, especially the initial milk, called colostrum, rich in immunoglobulin's that coat the gastrointestinal tract and protect the newborns until their own immune system starts properly functioning and creates a mild laxative effect, expelling meconium and preventing the buildup of bilirubin (9).

The World Health Organization (WHO) and UNICEF strongly recommend mothers to breastfeed their newborns within one hour after birth and continue doing so exclusively for the first six months of life (10, 11). Despite the aforementioned recommendations, the proportion of mothers who practiced EBF was $52.0 \%$ in 2011, and 58.0\% in 2016 based on the Ethiopian Demographic Health Survey reports (12-13). Although the 2016 survey report showed a slightly increment in the proportion of mothers to EBF the practice declined with age from $74 \%$ in $0-1$ months to $36 \%$ in $4-5$ months with some regional variations. A more recent pocket study in rural Ethiopia reported EBF practice of $43.6 \%$ which is even lower than the 2016 national fidings (14). It is important to note that the observed gap in EBF practice is not only due to lack of awarenesses-it is compounded by low physical access to health care facilities, economic, societal and cultural settings (15-18) are among other barriers to EBF practice. Such information however is limited in the studied area and thus we studied the level of EBF and its enabling for some programmatic improvements.

\section{Methods}

\section{Study area and population}

A facility based cross sectional study was conducted from June to July 2019 in Assosa town, the capital city of Benishangul-Gumuz (BG) among lactating mothers. BG is amongst the nine regional states of the Federal democratic republic of Ethiopia and is composed of 3 zones and 20 districts. This region shares common borders with the state of Amhara in the East, the Sudan in the North-East, and the state of Oromia in the South. The town has one public hospital and one health center which provide health care services for over 600,000 habitants. The study participants were all postnatal volunteer mothers who visited the facilities during the study period.

\section{Sample size determination, data collection, processing and analysis}

The sample size required was determined using single population proportion formula assuming a proportion of $34.7 \%$ were knowledgeable on EBF (19) with level of significance of $5 \%(a=0.05), 95 \%$ confidence level $(Z \mathrm{a} / 2=1.96)$ and absolute precision or margin of error of $5 \%(d=0.05)$ and $10 \%$ for nonresponse rate which inflated to 412 . Of these, 80 and 332 of the expected participants were distributed to 
the health center and the hospital, respectively proportionately and subsequently enrolled them in order of arrival until the required sample size was reached.

To standardize the data collection process, 2 days training was given for the health extension workers who were hired temporarily to serve as data collectors. Data on sociodemographic, obstetric factor, neonatal factor and culture related variables were collected from all sampled participants through face to face interview. Six practice questions were included in the tool to assess practice of EBF and distributed as; 1 ) breastfeed your last child (2 items); 2 ) initiation of breastfeeding (3 items); 3 ) frequency of BF (3 items); 4) substance given before initiating BF (2 items); 5) types of Prelacteal feeding (4 items) and 6$)$ child BF from 0-6 months only breast milk (2 items). The items in each construct were then added together, with equal weights, to generate the mean score and then categorized the collected information into good and poor EBF practices when the overall mean scores of the is above and below the mean, respectively.

Data were entered and analyzed using SPSS software version 25.0. Binary and Multiple logistic regressions was used to analyze the contributory factors for EBF. A p-value less than $5 \%$ was declared as statistically significant.

\section{Results}

\section{Sociodemographic Characteristics}

All the 412 enrolled mothers were interviewed and responded adequately with $100 \%$ response rate. The proportion of mothers belonging to the age of $26-35$ years was $70.1 \%$ and $165(40 \%)$ were Orthodox Christians. Less than a quarter $(20.1 \%)$ were unable to read and write and about one-third (30.3\%) were housewives. About half (47.6\%) were from rural settings and most $(76.5 \%)$ of them were earning below 5000 ETB 52.4 (Table 1). 
Table 1

Respondents sociodemographic characteristics

\begin{tabular}{|c|c|c|}
\hline Respondents Characteristics & Number & Percent \\
\hline \multicolumn{3}{|l|}{ Age of the mother } \\
\hline$<25$ years & 82 & 19.9 \\
\hline $26-35$ years & 289 & 70.1 \\
\hline $36-45$ and above & 41 & 10 \\
\hline \multicolumn{3}{|l|}{ Religion of the mother } \\
\hline Orthodox & 165 & 40.0 \\
\hline Muslim & 124 & 30.1 \\
\hline Catholic & 41 & 10.0 \\
\hline Protestant & 82 & 19.9 \\
\hline \multicolumn{3}{|l|}{ Marital status } \\
\hline Married & 306 & 74.3 \\
\hline Single & 33 & 8.0 \\
\hline Divorced & 65 & 15.8 \\
\hline Widowed & 8 & 1.9 \\
\hline \multicolumn{3}{|c|}{ Educational status of the mother } \\
\hline Unable to read and write & 83 & 20.1 \\
\hline Read and write & 163 & 39.6 \\
\hline Primary school & 58 & 14.1 \\
\hline Secondary school & 52 & 12.6 \\
\hline $10+2$ and above & 56 & 13.6 \\
\hline \multicolumn{3}{|l|}{ Maternal Occupation } \\
\hline Government Employee & 124 & 30.1 \\
\hline Private Employee & 163 & 39.6 \\
\hline House Wife & 125 & 30.3 \\
\hline \multicolumn{3}{|l|}{ Residency } \\
\hline Urban & 216 & 52.4 \\
\hline ETB-Ethiopian Birr (1 USD is $e$ & uivallen tc & 39 ETB) \\
\hline
\end{tabular}




\begin{tabular}{|llc|}
\hline Respondents Characteristics & Number & Percent \\
\hline Rural & 196 & 47.6 \\
\hline Income & & \\
\hline$<1500$ & 154 & 37.4 \\
\hline $1500-2500$ & 71 & 17.2 \\
\hline $2501-5000$ & 90 & 21.8 \\
\hline$>5000$ & 97 & 23.5 \\
\hline ETB-Ethiopian Birr (1 USD is equivallen to 39 ETB) \\
\hline
\end{tabular}

\section{Maternal Behavior Before and after Delivery}

Of the 412 respondents, the majority (88.1\%) were multi-gravida and above. Less than a quarter (26.0\%) had no antenatal care. The proportion of mothers who had three and more ANC was $61.9 \%$. Over half $(55.4 \%)$ had no postnatal care showing women's retention on the continuum of the maternal care pathway is low. The proportion of mothers who had normal range of gestational age, low birthweight and exclusively breastfed their children was $79.9 \%, 12.2 \%$ and $76.0 \%$, respectively (Table 2 ). 
Table 2

Maternal behavior before and after delivery

\begin{tabular}{|lcc|}
\hline Maternal Characteristics & Number & Percent \\
\hline Gravidity & & \\
\hline Primigravida & 49 & 11.9 \\
\hline Multigravida & 245 & 59.5 \\
\hline Grand multipara & 118 & 28.6 \\
\hline Antenatal care (ANC) & & \\
\hline None & 111 & 26.9 \\
\hline only one times & 43 & 10.4 \\
\hline Twice & 3 & 0.7 \\
\hline More than 3 & 255 & 61.9 \\
\hline Postnatal care (PNC) & & \\
\hline Yes & 184 & 44.7 \\
\hline No & 228 & 55.3 \\
\hline Gestational Age & & \\
\hline 32-37weeks & 83 & 20.1 \\
\hline 37- 42weeks & 329 & 79.9 \\
\hline Child birthweight & & \\
\hline < 2500 gm & 71 & 12.2 \\
\hline 2500-4000gm & 176 & 42.7 \\
\hline$>4000 g m$ & 20.6 \\
\hline Unknown & 85.0 \\
\hline Breastfed the child exclusively & \\
\hline Yes & 313 & 76.0 \\
\hline No & & \\
\hline
\end{tabular}

\section{Maternal Practice Towards Exclusive Breastfeeding}

Table 3 displays the maternal experiences towards EBF. Most (70.1\%) of the mothers breastfed their infants and 248(60.2\%) initiated BF immediately, and over one-third (39.8\%) fed their infants regularly 
ever $3-4$ hours. Eighty two (19.9\%) had provided pre-lacteal feeding of whome, $12.3 \%$ gave plain water, cow's milk in $10.9 \%$, butter in $24.4 \%$ and formula milk in $52.4 \%$. The overall aggregated good EBF practice score was $64.1 \%$, 
Table 3

Maternal practice towards Exclusive Breastfeeding

\begin{tabular}{|c|c|c|}
\hline Characteristics & Number & Percent \\
\hline \multicolumn{3}{|l|}{ Breastfeed the infant } \\
\hline Yes & 289 & 70.1 \\
\hline No & 123 & 29.9 \\
\hline \multicolumn{3}{|c|}{ Initiation of breastfeeding after delivery } \\
\hline Immediately & 248 & 60.2 \\
\hline Between 2 and 24 hours & 123 & 29.9 \\
\hline After 24 hours & 41 & 10.0 \\
\hline \multicolumn{3}{|l|}{ Frequency of breastfeeding } \\
\hline On demand & 124 & 30.1 \\
\hline Regularly every $3-4$ hours & 164 & 39.8 \\
\hline Randomly & 124 & 30.1 \\
\hline \multicolumn{3}{|l|}{ Pre-lacteal feeding } \\
\hline Yes & 82 & 19.9 \\
\hline No & 330 & 80.1 \\
\hline \multicolumn{3}{|c|}{ Types of Pre-lacteal feeding provided $(n=82)$} \\
\hline Plain water & 10 & 12.3 \\
\hline Cow milk & 9 & 10.9 \\
\hline Butter & 20 & 24.4 \\
\hline Formula milk & 43 & 52.4 \\
\hline \multicolumn{3}{|c|}{ Since birth to 6 months child was given } \\
\hline Breast milk only & 313 & 76.0 \\
\hline Formula milk & 99 & 24.0 \\
\hline \multicolumn{3}{|c|}{ Overall Practice of EBF score } \\
\hline Good & 264 & 64.1 \\
\hline Poor & 148 & 35.9 \\
\hline
\end{tabular}


Prior to the regression analysis, maternal responses on the six dichotomized practice questions were fit into the binary regression model. The output revealed that mothers that had education, from urban setting, had antenatal and postnatal follow-up, and gave birth to male child were significantly associated with practicing EBF. Nonetheless, in the multivariate regression analysis, only mothers who had completed primary schooling $[\mathrm{AOR}=4.5 ; 95 \% \mathrm{Cl}=1.1,18.2]$, had three and more $\mathrm{ANC}[\mathrm{AOR}=0.018 ; 95 \mathrm{Cl}=$ $0.003-0.12]$ and postnatal follow-ups[AOR $=0.218 ; 95 \% \mathrm{Cl}=0.07-0.67]$, and had delivered male infant $[A O R=2.3 ; 95 \% \mathrm{Cl}=1.0-4.95]$ retained their significant association with exclusive breastfeeding practice score. Although more mothers that had received information from health facilities adhered to EBF, there was no significant association with the EBF practice (Table 4). 
Table 4

Maternal and child factors contributing to practice exclusive breastfeeding

\begin{tabular}{|c|c|c|c|c|}
\hline \multirow[t]{2}{*}{ Characteristic } & \multicolumn{2}{|c|}{ EBF score } & \multirow[t]{2}{*}{ COR95\%Cl } & \multirow[t]{2}{*}{ AOR95\%Cl } \\
\hline & Good & Poor & & \\
\hline \multicolumn{5}{|c|}{ Education status of mother } \\
\hline Unable to read and write & 9 & 42 & 1 & 1 \\
\hline Read and write & 39 & 87 & $2(0.93-4.7)$ & $0.26(0.06-1.02)$ \\
\hline Primary school & 96 & 19 & $23.6(9.8-56.4) *$ & $4.5(1.1-18.2)$ * \\
\hline Secondary school & 49 & 57 & $4(1.8-9.06)$ * & $0.54(0.13-2.35)$ \\
\hline $10+2$ and above & 13 & 1 & $60(7.01-524.8)$ * & $8.5(0.77-94.3)$ \\
\hline \multicolumn{5}{|l|}{ Residency } \\
\hline Urban & 133 & 83 & $2.7(1.8-4.02)$ * & $2.3(1.17-04.56)$ \\
\hline Rural & 73 & 123 & 1 & 1 \\
\hline \multicolumn{5}{|c|}{ Frequency of ANC follow up } \\
\hline None & 18 & 93 & 1 & 1 \\
\hline One & 3 & 40 & $0.12(0.06-0.23)$ * & $0.14(0.06-0.36)$ * \\
\hline Twice & 0 & 3 & $0.046(0.013-0.16)$ * & $1.7(0.86-3.5)$ \\
\hline Three and more & 185 & 70 & $2.2(1.4-3.6) *$ & $0.02(0.003-0.12)$ * \\
\hline \multicolumn{5}{|l|}{ Infant gender } \\
\hline Female & 80 & 111 & 1 & 1 \\
\hline Male & 126 & 95 & $0.54(0.36-0.8)$ * & $2.3(1.0-4.95)$ * \\
\hline \multicolumn{5}{|l|}{ Received PNC } \\
\hline Yes & 105 & 166 & $2.4(1.55-3.55)$ * & $0.22(0.07-0.67)$ * \\
\hline No & 45 & 88 & 1 & 1 \\
\hline \multicolumn{5}{|l|}{ Source of information } \\
\hline Friends & 44 & 41 & 1 & 1 \\
\hline Mass media & 48 & 80 & $0.55(0.32-0.97)$ & $1.7(0.6-5.4)$ \\
\hline Facilities & 114 & 85 & $1.25(0.75-2.18)$ & $0.7(0.29-1.75)$ \\
\hline
\end{tabular}




\section{Discussion}

The world health organization adopted a comprehensive strategy called the Continuum of Care to improve reproductive, maternal, neonatal, and child health (20-21). In view of this, we studied the behavior of lactating mothers EBF practice and the factors enabling towards ood practive among mothers who recently delivered in the two available health facilities of the town. Based on our findings, about three-fourth adhered to EBF which indicates that present finding is better than the the 2016 national figure reported by Ethiopian Demographic Health Survey report (13) which was $58 \%$. It is likely to see such discrepancies since the nature of the sampled mothers enrolled in our study were all from health facilities suggesting that they all had probably accessed the services provided and to some extent attributed to their awarenesses about the importance of breastfeeding.

Though breastfeeding is almost universal in Ethiopia and exclusive breastfeeding up to 6 months after birth is an important contraceptive method, the status of exclusive breastfeeding in the studied area as well as in the country is less than the global recommendations (22) calls for more focused advocacy work to be done in this regard.

The good practice when compared with previous studies report, our study is concordant with MizanAman town findings which reported $60.2 \%$ of the mothers to initiate breastfeeding immediately within an hour $(60.2 \%$ vs $60.1 \%)$. The similarity of the findings is attributed to the fact that all the sampled mothers are from health facilities where they had access to appropriate councelling on newborn feedings $(19,23)$ though still more is expected to achiev a better result and maximize the benefites of EBF.

In this study, pre-lacteal feeding (PF) observed is higher compared to the findings reported by other authors $(18,22-24)$. The differences may be attributed to time constrains emanating from work related activities - most mothers with better education often get better job with better income and often such mothers rush to their work and consequently forced to practice PF. There could be others as well which need further expoloratory study. The most common PF given in this study was plain water, cow's milk, butter and formula milk. Compared with the Mizan Aman findings on provision of water $(12.3 \%$ vs 48.2 $\%$ ), and cow's milk ( $24.4 \%$ vs $50.2 \%)$, our finding is by far better. These difference might be due to the socioeconomic factors and to some extent to maternal awareness towards EBF though needs further study.

The major enabling factors or that influenced mothers to adhere to EBF were education, proper antenatal and postnatal cares, and infant's gender. Mothers who had primary education were 4.5 time more likely to adher to EBF than their counterparts. Although the education system differs and various experiences exist across the world, some studies reported maternal and paternal educational attainment as a common predictor for maternal service utilization in developing countries including Ethiopia (25-26).

Mothers who had 3 or more antenatal follow-up were 20 percent more likely practicing EBF than those who had none. In the same breath, mothers who had postnatal follow-up also were $22.0 \%$ more likely practicing EBF than those who had no PNC. Some previous studies documented service utilization of 
mothers to be low particularly among rural women due to the high domestic workload and little time left after attending to essential household chores until term and beyond (27-28).

Interestingly, mothers who delivered male infant were observed to practice 2.3 times more likely than those who delivered females probably due to cultural preferences for males. Unexpectedly, although more mothers that had received information from health facilities adhered to EBF, there was no significant association with the maternal practice of EBF in our study probably due to an unfocussed councelling/ less trained health educators. This is in contrary to some previous studies where they reported some associations and thus needs to be interpreted cautiously $(15,26)$. Therefore, this calls for further exploratory study to uncover why the sources of information did not bring the desired/expected change toward EBF practice.

\section{Strength and Limitations}

The strength of the study is that it included the available health facilities in the town and has generated some new evidence for programmatic implications to improve the EBF practice in the region. The information generated would be a bench mark for future studies as well. Despite the aforementioned strengths, the findings had some limitations and thus need to be interpreted cautiously since facilitybased studies as well as the design employed may make estimates unstable and associations between dependent and independent variables undetectable.

\section{Conclusion}

The study has highlighted that women's retention on the continuum of the maternal care pathway is low with about a quarter of mothers not practicing EBF. The major determinants identified to enabled mothers to adhere to EBF were education, antenatal and postnatal cares and infant's gender. To narrow the disparities observed among mothers and their children, it is essential to intervene through focused actions that address the above determinants by all stakeholders since the issue is a cornerstone of public health and it has been reiterated at many international conferences and initiatives to lower morbidities and mortlities of mothers and children (28-29).

\section{Abbreviations}

ANC: antenatal Care

AOR: Adjusted Odds Ratio

BG: Benishengul-Gumuz

BM: Breastmilk

EBF: Exclussive Breastfeeing 
ETB: Ethiopian Birr

PF: Prelacteal Feedings

PNC: Postnatal Care

\section{Declarations}

\section{Acknowledgments}

The authors would like to thank the study participants and the respective health bureaus and health facilities including Sante medical college for their kind support to carry out this study.

\section{Authors contribution}

MK has collected the data and drafted the MS while JH has supervised the work and critically reviewed the draft for the intellect and submitted the MS. All authors had approved the final version of the MS.

\section{Funding Sources}

The authors report no external funding source for this study.

\section{Availability of data and materials}

All data generated or analysed are included in this published article.

\section{Ethics approval and consent to participate}

Ethical clearance and approval was obtained from Ethical approval committee of Sante medical college as well as from all relevant sectors of BG Regional state. Each study participant was adequately informed about the purpose, methods, and anticipated benefits of the study by the data collectors. Written informed consent was also obtained from all respondents who volunteer and were available at the time of data collection. All participants were interviewed without writing their names to ensure confidentiality. In addition, mothers with poor EBF practice were councelled upon completion of the study. All methods were carried out in accordance with relevant guidelines and regulations.

\section{Consent for publication}

Not applicable.

\section{Competing interests}

The authors declare that they have no competing interests.

\section{Declaration of interest}


No conflict of interest.

\section{References}

1. World Health Organization. Indicators for assessing breast-feeding practices. Report of an informal meeting. Geneva, Switzerland: 1991.

2. Salami L. Factors influencing breastfeeding practices in Edo state, Nigeria. African Journal of Food, Agriculture, Nutrition and Development 2011;6(2) doi: 10.4314/ajfand.v6i2.71755.

3. Lavender T, McFadden C, Baker L. Breastfeeding and family life. Maternal \& Child Nutrition 2006;2(3):145-155. doi: 10.1111/j.1740-8709.2006.00049.

4. McFadden A., Toole G. Exploring women's views of breastfeeding: a focus group study within an area with high levels of socio-economic deprivation. Maternal \& Child Nutrition 2006;2(3):156-168. doi: 10.1111/j.1740-8709.2006.00054.

5. Ball T. M., Bennett D. M. The economic impact of breastfeeding. Pediatric Clinics of North America2001;48(1):253-262. doi: 10.1016/S0031-3955(05)70298-4.

6. Jones J. M. The methodology of nutritional screening and assessment tools. Journal of Human Nutrition and Dietetics2002;15(1):59-71. doi: 10.1046/j.1365-277X.2002.00327.

7. Kull I., Wickman M., Lilja G., Nordvall S. L., Pershagen G. Breast feeding and allergic diseases in infants-a prospective birth cohort studyArchives of Disease in Childhood2002;87(6):478-481. doi: 10.1136/adc.87.6.478.

8. Tampah-Naah A. M., Kumi-Kyereme A. Determinants of exclusive breastfeeding among mothers in Ghana: a cross-sectional study. International Breastfeeding Journal2013;8(1, article no. 13) doi: 10.1186/1746-4358-8-13.

9. Kong S. K. F., Lee D. T. F. Factors influencing decision to breastfeedJournal of Advanced Nursing 2004;46(4):369-379. doi: 10.1111/j.1365-2648.2004.03003.

10. World Health Organization. Innocent declaration on the protection, promotion and support of breastfeeding. Geneva, Switzerland: 1990.

11. World Health Organization. World Health Organization: 10 facts on child health. Geneva, Switzerland: World Health Organization; 2012.

12. Central Statistical Agency [Ethiopia] and ICF International, Ethiopia demographic and health survey, 2011. Addis Ababa, Ethiopia and Calverton, Maryland, USA.

13. Ethiopian Demographic and Health Survey, 2016. Key Indicators Report Central Statistical agency Addis Ababa, Ethiopia: the DHS Program ICF Rockville, Maryland, USA.

14. Tsedeke W, Gadisa D, Ababa W, Genet M, Girma N. Knowledge, Attitude and Practice of Exclusive Breast Feeding Among Lactating Mothers in Bedelle Town, Southwestern Ethiopia: Descriptive Cross Sectional Study 2014; [MPH Thesis].

15. Chukwuma A, Wosu AC, Mbachu C, Weze K. Quality of antenatal care predicts retention in skilled birth attendance: a multilevel analysis of 28 African countries. BMC pregnancy and childbirth 
2017;17(1):152.

16. Banke O.E, Ameh CA. Factors influencing utilisation of maternal health services by adolescent mothers in Low-and middle-income countries: a systematic review. BMC pregnancy and childbirth. 2017;17(1):65.

17. Sheffel A, Karp C, Creanga AA. Use of Service Provision Assessments and Service Availability and Readiness Assessments for monitoring quality of maternal and newborn health services in lowincome and middle-income countries. BMJ global health 2018;3(6):e001011.

18. Sakuma S, Yasuoka J, Phongluxa K, Jimba M. Determinants of continuum of care for maternal, newborn, and child health services in rural Khammouane, Lao PDR. PloS one 2019;14(4).

19. NiguseT, Frehiwot $H$, Dinu A, Eyerus D. Knowledge, attitude and practice towards exclusive breastfeeding among lactating mothers in Mizan-Aman town, Southwestern Ethiopia: descriptive cross-sectional study. International Breastfeeding Journal 2016; 11:3 DOI 10.1186/s13006-016-00620 .

20. WHO. The World Health Report 2005: Make every mother and child count: World Health Organization; 2005.

21. WHO. WHO recommendations on antenatal care for a positive pregnancy experience. World Health Organization Geneva, Switzerland; 2016.

22. Alebel A, Tesma C, Temesgen B, Ferede A, Kibret GD. Exclusive breastfeeding practice in Ethiopia and its association with antenatal care and institutional delivery: a systematic review and meta-analysis. International breastfeeding journal. 2018;13(1):31.

23. Maeza M, Mesele A, Zelalem K. Factors associated with exclusive breastfeeding practices in DebreBerhan District, Central Ethiopia: a cross sectional community based study International Breastfeeding Journal 2015); 0: 23.

24. Tadele N, Habta F, Akmel D, Deges E. Knowledge, Attitude and Practice towards Exclusive Breastfeeding among Lactating Mothers, Mizan-Aman Town, Southwestern Ethiopia: Descriptive Cross Sectional Study. J Health Edu Res Dev 2015;(3):149 doi:10.4172/2380-5439.1000149.

25. Fekadu GA, Ambaw F, Kidanie SA. Facility delivery and postnatal care services use among mothers who attended four or more antenatal care visits in Ethiopia: further analysis of the 2016 demographic and health survey. BMC pregnancy and childbirth. 2019;19(1):64.

26. Alemi K, Tekle-Haymanot A. Factors associated with institutional delivery service utilization in Ethiopia. International journal of women's health 2016;8:463.

27. Ousman SK, Magnus JH, Sundby J, Gebremariam MK. Uptake of Skilled Maternal Healthcare in Ethiopia: A Positive Deviance Approach. International journal of environmental research and public health 2020;17(5):1712.

28. Rosenfield A, Min CJ. A history of international cooperation in maternal and child health. Maternal and child health, Springer 2009; 3-17.

29. Kerber KJ, de Graft-Johnson JE, Bhutta ZA, Okong P, Starrs A, Lawn JE. Continuum of care for maternal, newborn, and child health: from slogan to service delivery. The Lancet. 
2007;370(9595):1358-69.

Page 17/17 